\title{
Reliability of water fittings in operating conditions
}

\author{
Alexander Svintsov ${ }^{1 *}$, Evgeniy Alekseev ${ }^{2}$, Svetlana Shambina ${ }^{1}$, Roman Fediuk ${ }^{3}$ and \\ Vladislav Fominov ${ }^{1}$ \\ ${ }^{1}$ Peoples' Friendship University of Russia (RUDN University), Moscow, Russia \\ ${ }^{2}$ Moscow State University of Civil Engineering, Yaroslavskoe shosse, 26, Moscow, 129337, Russia \\ ${ }^{3}$ Far Eastern Federal University, 8, Sukhanova St., Vladivostok 690950, Russia
}

\begin{abstract}
Water fittings are an integral part of the internal water supply system. The reliability of their work under operating conditions largely influence on the continuity of water supply to the population. The reliability indicators of sanitary fittings allow the services responsible for the technical condition of the indoor water supply of houses to pay priority attention to the factors that determine the uninterrupted water supply of the population and reduce the loss of drinking water. In this study, the results of indicators of operational reliability of faucets for sinks in kitchens and washbasins in toilet rooms of apartments of multi-store residential buildings in a residential neighborhood are presented. The study was performed based on the analysis of records in the logs of data on valve failures for 2016-2018. The main malfunctions are established, the random coincidence of which leads to failures. The reliability of sanitary fittings is affected not only by their structure and the characteristics of the materials, as well as by the exploitation conditions. The probability of failure-free operation of sanitary fittings in exploitation conditions for a time not exceeding the duration of the reduction of water supply to consumers in residential buildings is the basic parameter of its reliability.
\end{abstract}

\section{Introduction}

Most of the sanitary equipment is equipped with faucets and taps. In this regard, faucets and taps are a key element of water saving. Depending on the type of these elements and their serviceability, there are differences for water consumed $[1,2,3]$. The uninterrupted functioning of the internal water supply systems of residential buildings largely depends on the reliability of the water fittings. The technological innovations with water saving purpose in water supply appliances analyzed in [4]. Investigations of the reliability and replacement interval of flexible hose assemblies for washbasins, sinks and water closets when using cold and hot water supply presented in [5]. The analysis of scientific and technical literature shows that the issues of trustworthiness of sanitary fittings in operating conditions not sufficiently investigated.

\footnotetext{
* Corresponding author: svintsovap@rambler.ru
} 


\section{Main part}

Different accidental incidents and procedures disrupt the functioning of the sanitary equipment $[6,7]$. At present, direct inspection of the state of sanitary fittings in residential buildings is associated with significant organizational difficulties. In this connection, the selection, examination and analyzing of statistical data on the functioning of water fittings under operating conditions is the only way to estimate the parameters of their dependability. The following information is recorded in the logs: date of application acceptance, fault address, the contact phone number, the content of the application, the time of the application's receipt, the time of work, the name of the repairing plumber and the consumption of materials. The control room serves 1,794 apartments in five block of flats. The flats are equipped with a typical set of sanitary equipment: a sink, a bath and a washbasin, a toilet with a flushing tank. They are equipped with faucets and taps.

The defining criterion for the operational reliability of sanitary and technical fittings is their ability to perform the intended functions for a given period, while maintaining their properties. Reliability standards are formal and objective indicators that characterize the normative functioning of fittings when using tap water. The evaluation of the dependability parameters of sanitary fittings is made based on the reliability theory and the exponential law of the allocation of values about its technical condition.

Water fittings are a type of recoverable equipment. The quantitative indicator of the reliability for the period $t$ is the indicator $P(t)$ which is the probability of failure-free operation from the beginning of work to failure. In this case, the flow of water fittings' failures is an ordinary one, since the next failure can occur only after the device is restored. In this regard, the expressions that determine the main indicators of reliability have the form [8]:

$$
\begin{aligned}
& \lambda(t)=\lambda=\text { const } \\
& P(t)=e^{-\lambda t} \\
& Q(t)=1-e^{-\lambda t} \\
& P(t)=\frac{(\lambda t)^{k}}{k !} e^{-\lambda t} \\
& \omega(t)=\lambda \\
& t_{\text {H.o. }}=t_{o}
\end{aligned}
$$

The peculiarity of obtaining primary information based on the analysis of records in the dispatch service logs is the need to find and identify damage to water fittings. During the study, some restrictions were adopted that consider the features of records that are not taken into account in the analysis: simple replacement of serviceable water fittings, as well as the impossibility of identifying a malfunction due to its ambiguous qualitative description or unclear information about the materials consumed.

When analyzing the records, the data were obtained for a three-year observation period (2016 - 2018) and the main malfunctions were established, as the accidental coincidence of them leads to failures. After identifying the damage to water fittings according to the records in the dispatch service logs, the preliminary statistical processing of the data was performed: calculation of sample middle means, middle-quadratic deviations and confidence intervals. Another important point of statistical processing was the elimination of gross errors that are possible when rewriting data into the observation protocols. For effective and correct use of the observational data, statistical hypotheses were tested to determine the distribution law. 
The experience of operating of internal water supply systems shows that the following elements most often fail: shut-off pair of a piston-type valve head, a spindle seal, a faucet flow switch for a washbasin and a bathtub, an sealing ring in the spout attachment to the faucet body, a flexible hose for a washbasin and sink faucet, a shower net on a flexible hose. The indicated malfunctions do not equally affect the functioning of the faucets during operation. In this aspect, the reliability of water fittings is closely related to ensuring proper conditions for water use. The loss of the ability of faucets to perform their functions leads to the formation of leaks of tap drinking water, its unproductive use and to an adverse psychological effect on users. When paying for water consumption according to meter readings, users are interested in eliminating water leaks, because they be to pay for water losses without using it. Figure 1 shows the valve of faucets, the most widely used in the systems of water equipment of residential buildings.
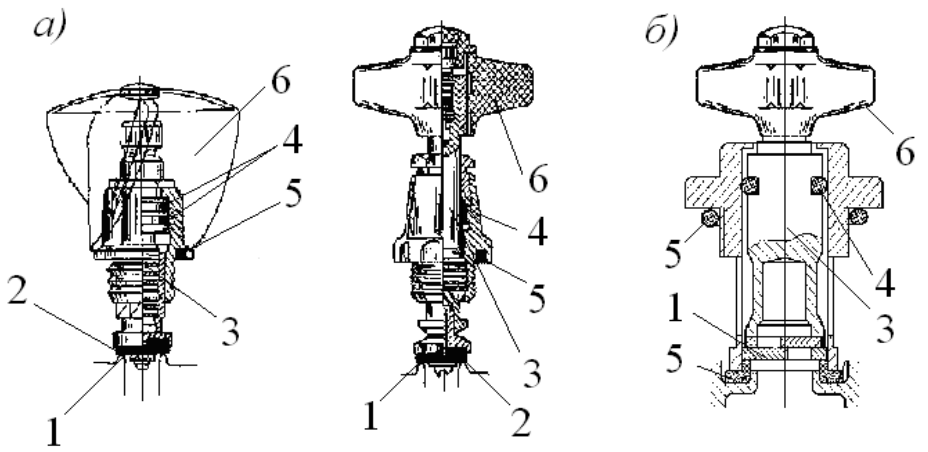

Fig. 1. Valve of faucets: a) a piston type; b) a washer type; 1 - shut-off pair; 2 - rubber gasket; 3 spindle; 4 - spindle seal; 5 - clamping rubber ring; 6 - handle.

A shut-off pair (rubber - metal) of a piston-type valve head (Fig. 1a) fails most of all due to abrasion or crumpling of the rubber gasket, the formation of irregularities on the working surface from cavitation shells in the valve seat of the shut-off element. These damages lead to water leaks, as well as to non-productive water consumption in the process of adjusting the required flow rate and water temperature.

The violation of sealing on the spindle leads to the fact that when the faucet is open, water not only flows out through the spout, but also flows out from under the clamping nut. This malfunction does not cause large losses of water, but it creates inconvenience when using the fittings and gradually leaves traces of carbonate deposits on the fittings and water appliances.

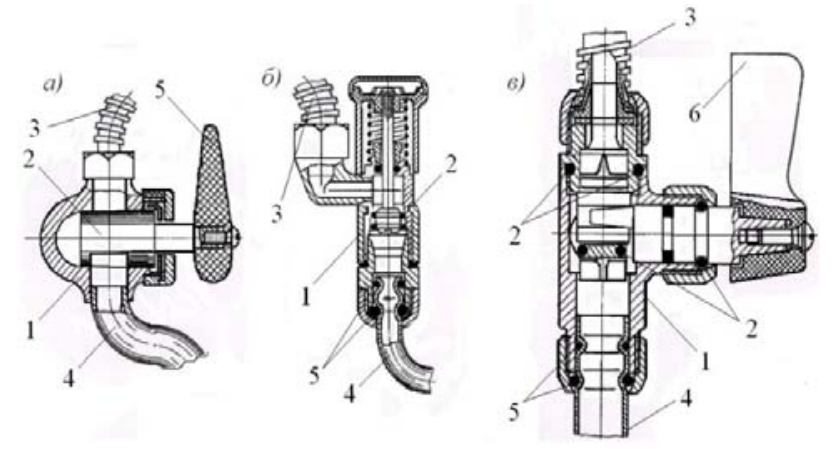

Fig. 2. Flow switches: a) cork; 1 - case; 2 - cork; 3 - braided flexible hose; 4 - spout; 5 - handle; b) push-button; 1 - case; 2 - valve; 3 - flexible hose; 4 - spout; 5 - rubber rings (seals); c) spool valve; 1 - case; 2 - rubber rings (seals); 3 - flexible hose; 4 - spout; 5 - rubber rings (seals); 6 - handle. 
A malfunction of the flow switch (Fig. 2) does not allow normal use of the faucet for the washbasin and bath. The type of malfunction depends on the design of the faucet: pushbutton, cork, spool valve. The most common failures are the rubber rings of the valve, spool valve or cork seal.

Violation of the tightness of the spout connection unit to the mixer body (Fig. $3 a$ ) is caused by abrasion or fatigue deformations of the sealing rings. Usually, the fault occurs as the flow of water of different intensity from under the pressure nut when the valve is open.

The flexible hose (Fig. 3 b) fails most often due to cracks or fistulas in the rubber tube located inside the metal braid. The metal braid can be damaged in the form of kinks or divergence of the turns. The rubber seal rings in the compression nuts lose their properties due to fatigue deformations.
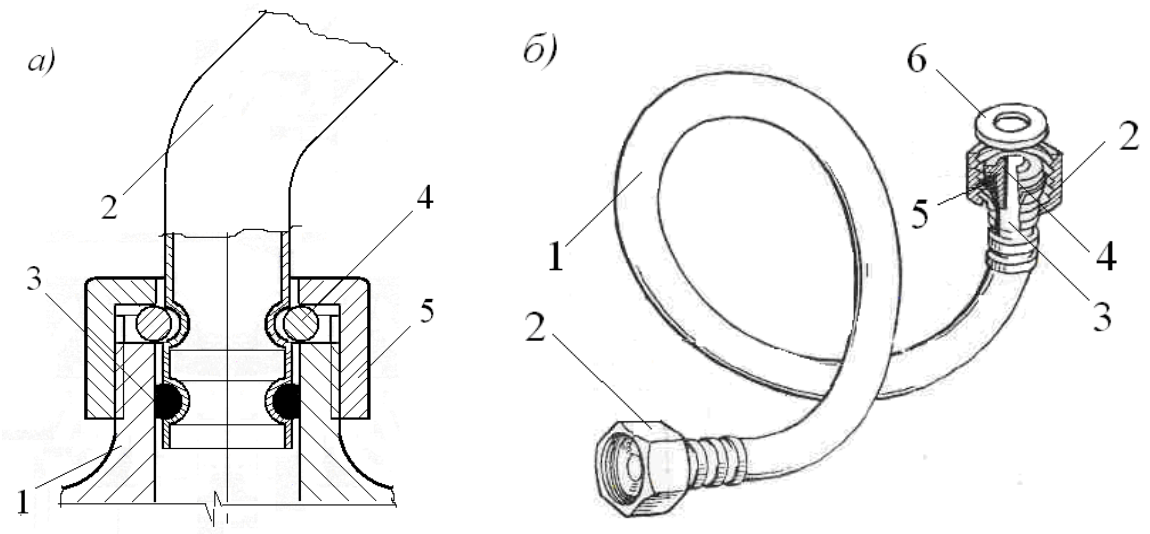

Fig. 3. Elements of the faucet: a) unit for attaching the spout to the case; 1 - faucet case; 2 - spout; 3 rubber ring (spout seal); 4 - retaining ring; 5 - clamping nut; b) flexible hose; 1 - braid; 2 - clamping nut; 3 - rubber tube; 5 - rubber ring (seal); 6 - rubber gasket (seal).

The shower mesh is most often covered with carbonate deposits, narrowing the holes, and is also clogged with pipe corrosion particles transported by the water. In some cases, the tightness of the connection of the shower net to the handle of the flexible hose is broken. In the event of a malfunction of the shower mesh, water loss is usually negligible.

Individual parts of sanitary fittings that carry out local functions in the unit are called elements. The division of fittings into components makes it possible to identify the least wear-resistant ones and assess their part to reliability parameters. An event involving a malfunction of a valve is called a failure. The numerical evaluation of the indicators of the reliability of sanitary fittings is performed on the foundation of the exponential law of the allocation of data on malfunctions of one type or another. In this case, the formulation of the failure of water fittings is as follows: $P(t)>0.7$. Reducing the probability of failure-free operation of the valve is considered its failure. Table 1 shows the data on the failure rate of sanitary fittings and their components, derived from the analysis of operation in accordance with the operating conditions. The confidence level when calculating the failure rate $\lambda$ is taken $\delta=0.95$. These tables can be employed to make forecasts of changes in the condition of sanitary fittings according to the operating conditions.

According to numerous expert assessments, the most loaded in terms of operation is the faucet fittings for sink in the kitchen. In this regard, the main feature of the reliability of faucets is faultlessness. The computation of the probability of trouble-free operation of faucet is made in accordance with the scheme: rubber gasket of a piston-type locking pair; seat of the piston-type locking pair; spindle seal; spout sealing ring; spout clamping nut. 
Table 1. Failure rates of water fittings under operating conditions.

\begin{tabular}{|c|c|c|c|}
\hline \multirow[t]{2}{*}{ Name of fitting and its elements } & \multicolumn{3}{|c|}{ Failure rate, $\lambda^{*} 10^{-4}$, days ${ }^{-1}$} \\
\hline & $\lambda_{\min }$ & $\lambda_{a v}$ & $\lambda_{\max }$ \\
\hline Faucet for sink & 4.55 & 6.11 & 9.07 \\
\hline Valve of piston type & 3.83 & 4.70 & 5.27 \\
\hline rubber gasket for closure member & 3.43 & 3.64 & 3.85 \\
\hline valve seat for closure member & 0.02 & 0.024 & 0.05 \\
\hline spindle sealing ring & 0.38 & 1.03 & 1.37 \\
\hline Valve of washer type & 0.47 & 0.66 & 1.55 \\
\hline washer for closure member & 0.09 & 0.12 & 0.34 \\
\hline spindle sealing ring & 0.38 & 0.54 & 1.21 \\
\hline Node spout attachment to the body & 0.25 & 0.75 & 2.25 \\
\hline sealing rings & 0.22 & 0.72 & 2.21 \\
\hline clamping nut & 0.03 & 0.03 & 0.04 \\
\hline Faucet for washbasin and bath & 5.86 & 8.57 & 14.31 \\
\hline Valve of piston type & 4.00 & 5.09 & 5.55 \\
\hline rubber gasket for closure member & 3.60 & 3.84 & 4.05 \\
\hline valve seat for closure member & 0.02 & 0.024 & 0.05 \\
\hline spindle sealing ring & 0.38 & 1.22 & 1.45 \\
\hline Valve of washer type & 0.51 & 0.80 & 1.71 \\
\hline rubber gasket for closure member & 0.08 & 0.13 & 0.36 \\
\hline spindle sealing ring & 0.43 & 0.67 & 1.35 \\
\hline Node spout attachment to the body & 0.70 & 0.84 & 2.25 \\
\hline sealing rings & 0.67 & 0.81 & 2.21 \\
\hline clamping nut & 0.03 & 0.032 & 0.04 \\
\hline Flow switchers & 0.32 & 0.92 & 2.45 \\
\hline valve & 0.004 & 0.006 & 0.008 \\
\hline bung & 0.004 & 0.005 & 0.006 \\
\hline spool & 0.004 & 0.013 & 0.033 \\
\hline sealing rings & 0.31 & 0.90 & 2.40 \\
\hline Flexible hose & 0.33 & 0.92 & 2.35 \\
\hline rubber hose & 0.01 & 0.013 & 0.02 \\
\hline metal braid & 0.004 & 0.008 & 0.009 \\
\hline gasket & 0.004 & 0.005 & 0.008 \\
\hline sealing ring & 0.31 & 0.90 & 2.31 \\
\hline choke & - & - & - \\
\hline
\end{tabular}

In the practice of determining the reliability indicators of water supply systems and plumbing equipment, the main unit of failure rate is $h^{-1}$. This is stipulated to the opportunity of an empirical define the operating time of the equipment in hours. When determining the reliability indicators of faucet fittings under operating conditions, it seems expedient to take $d a y^{-1}$ as a unit for measuring the failure rate. When designing faucet fittings, reliability indicators are determined in "open-closed" cycles. However, in accordance with the operating conditions, it is not possible to define the number of cycles with acceptable confidence. It is more convenient to estimate the intervals between repairs in days. From these considerations, the proposed unit of measurement is $d a y^{-1}$. Analysis of statistical data on failures of individual faucet fittings elements shows that the failure rate $\lambda$ ranges from $\lambda_{\min }=4.8^{*} 10^{-4}$ days $^{-1}$ to $\lambda_{\max }=8.4 * 10^{-4}$ days $^{-1}$ with an average value of $\lambda_{a v}=6.35^{*} 10^{-4}$ days $^{-1}$. Fig. 5 shows a generalized diagram of the empirical distribution of failure rates faucets for sinks. 
Low values of the failure rate indicator from April to August may be associated with the spring and summer rhythm of life. The accelerated rise in the failure rate in the autumn period is associated with the resumption of active use of sanitary fittings. In addition, some consumers prepare their household's engineering equipment for winter and seek services from specialists. Consumers on their own make minor repairs, consisting in replacing gaskets or gland packing, and sometimes even replacing valve of the faucet fitting, in some cases.

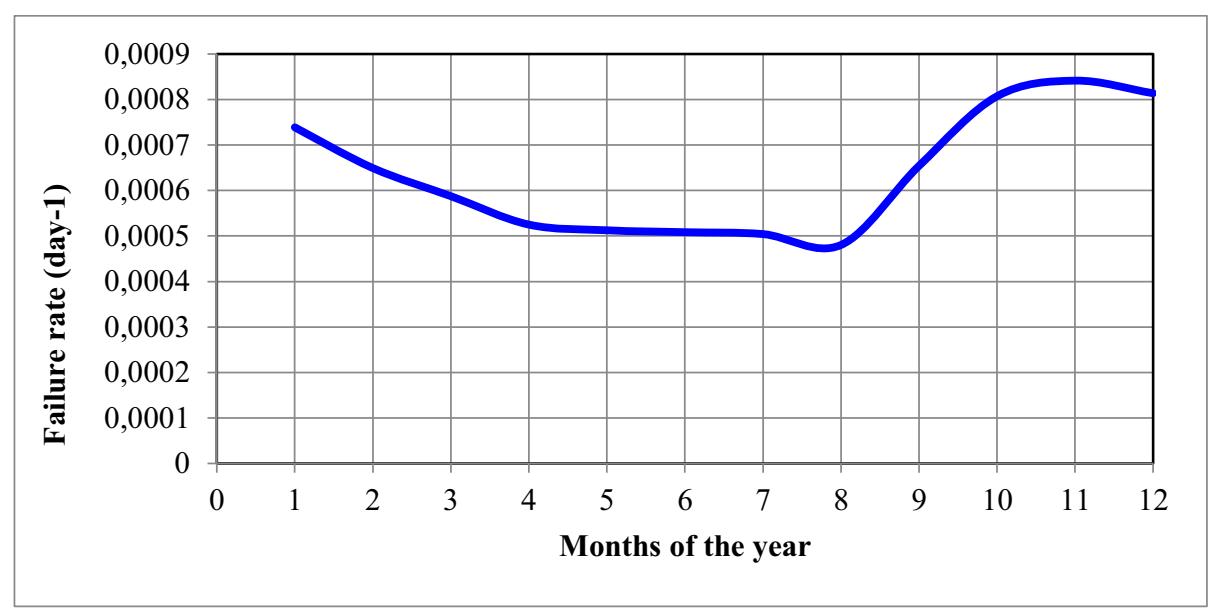

Fig. 5. Change in the failure rate of faucet fittings in the operating conditions of residential buildings.

Figure 6 shows diagrams for evaluating the failure-free function of mixers in operational conditions. The diagram shows that the empirical allocation of the possibility of failure-free operation of faucet fittings according to the generalized actual data is in the range of assured operation frameworks.

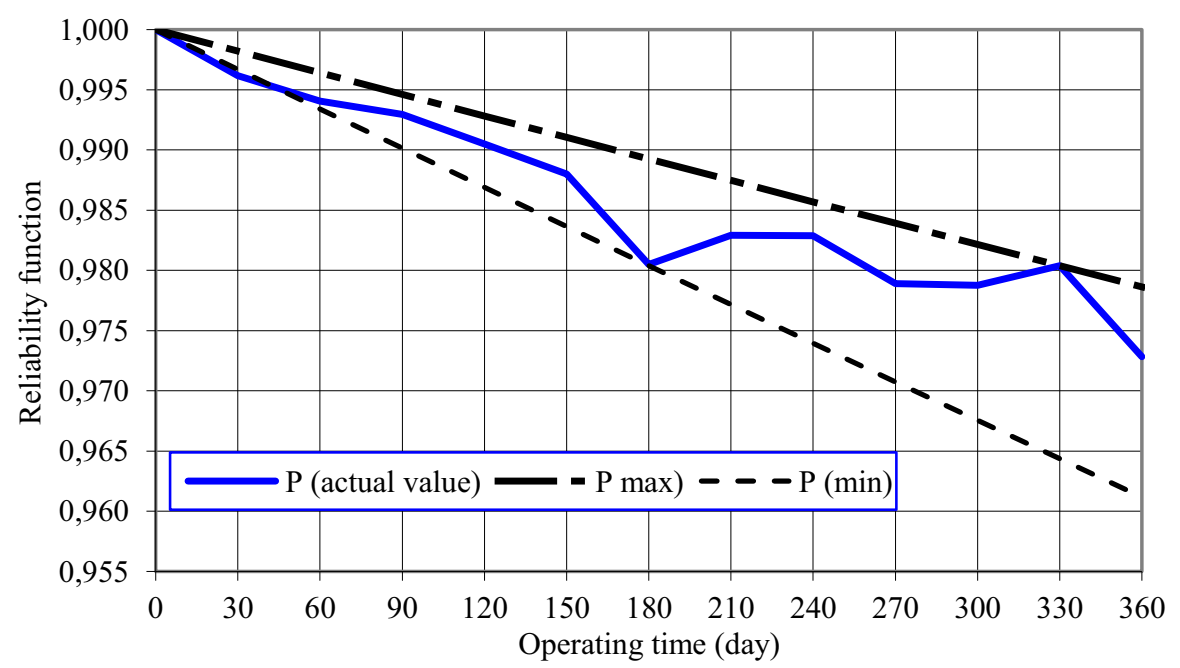

Fig. 6. Assessment of the possibility of trouble-free work of faucets in time.

\section{Conclusion}

According to the operating data, the guaranteed probability of trouble-free operation of mixers with piston-type valve heads is at least $\mathrm{P}=0.746$, which is above the emergency value set in the failure statement. 
Not only the construction and the materials used for this purpose, but also the conditions of use affect reliability of sanitary fittings. The article presents the results of a research on the patterns of changes in the reliability indicators of mixing fittings for sinks in kitchens and washbasins in toilet rooms of apartments of multi-store residential buildings in a residential neighborhood. The following conclusions were made:

1. The use of indicators of the reliability of sanitary fittings allows the technical services of operation to focus on the most significant reasons that affect the uninterrupted supply and the provision of appropriate conditions for water use of the population.

2. The foundation for selection of a rational design strategy for the maintenance of the domestic plumbing systems of residential buildings in working condition is the analysis of the indicators of the reliability of sanitary fittings in operational conditions.

3. The fundamental sign of the dependability of plumbing fittings under running conditions is the probability of faultless operation for a time not exceeding the duration of the reduction in the supply of water to consumers in residential buildings.

\section{References}

1. M.S. Kamer, A. Kaya, A. Sisman, Int. J. Scientific Tech. Res. 4 (10) 189-196 (2015)

2. S. Englart, A. Jedlikowski, SN Appl. Sciences 1525 (2019)

3. A.P. Svintsov, N.A. Konoplev, J. Mech. Cont. Math. Sc. 1S 527-536 (2019)

4. G. S. De Sousa Bottega, F.S. Bianchet, C.A. Jacoski, M.F. Costella, J. Inn. Sustainability. 10 (3) 129-147 (2019)

5. R. Błażejewski, R. Matz, T. Nawrot, D. Rudzik, Eng. Fail. Anal. 109104327 (2020)

6. A.P. Svintsov, N.A. Konoplev, J. Ur. Environ. Eng. 12 (2) 231-235 (2018)

7. A.P. Svintsov, V.A. Fominov, J. Phys.: Conf. Ser. 1687012035 (2020)

8. V.E. Gmurman, Probability theory and mathematical statistics (Moscow, 2014) 